\title{
SOLITARY EPIPHYSEAL PEDUNCULATED OSTEOCHONDROMA WITH SECONDARY OSTEOARTHRITIS: A CASE REPORT
}

Rajesh Kumar V1, Vasu C. K², Pavithran V. K³, Navas K. M4, Fathima J5

\section{HOW TO CITE THIS ARTICLE:}

Rajesh Kumar V, Vasu C. K, Pavithran V. K, Navas K. M, Fathima J. "Solitary Epiphyseal Pedunculated Osteochondroma with Secondary Osteoarthritis: A Case Report". Journal of Evolution of Medical and Dental Sciences 2015; Vol. 4, Issue 33, April 23; Page: 5779-5782, DOI: 10.14260/jemds/2015/846

ABSTRACT: Osteochondroma is the relatively common bone tumor arising from the metaphysis of long bones. Osteochondroma arising from epiphysis of long bones are very rare. We report a case of a 67 year old man with history of right shoulder pain for past 5 years and difficulty in moving the arm for past 1 year. X-ray showed severe osteophytic changes and a subtle bony outgrowth from head of humerus. MRI showed cartilage capped bony outgrowth arising from the epiphysis of humerus. Medullary cavity of the lesion is seen communicating with the medullary cavity of bone consistent with osteochondroma.

KEYWORDS: Osteochondroma, epiphysis, medullary bone, metaphysic, cartilage cap.

INTRODUCTION: Osteochondroma is the relatively common bone tumor arising from the metaphysic of long bones. It is usually found in growing skeleton. Osteochondroma arising from epiphysis of long bones are very rare. Only few cases of solitary epiphyseal osteochondroma have been reported in literature. We present a case of solitary epiphyseal osteochondroma with secondary osteoarthritis which was diagnosed incidentally when patient undergone MRI shoulder for shoulder pain.

CASE REPORT: A 67 years old male presented with complaints of right shoulder pain for past 5 years and difficulty in moving the arm for past 1 year. X ray showed severe osteophytic changes and a subtle bony outgrowth arising from head of humerus extending inferiorly along the medial aspect of humerus. We have taken MRI right shoulder which showed a cartilage capped bony outgrowth arising from the epiphysis of humerus. Medullary cavity of the lesion is seen in communicating with medullary cavity of bone. Cartilage cap thickness is $5 \mathrm{~mm}$. Severe osteoarthritic changes noted. Rotator cuff tendons and labrum are normal.

DISCUSSION: Osteochondromas are the most common primary bone tumors constitute more than one third of all benign bone tumors.(1). Osteochondroma can be solitary or multiple. Multiple osteochondromas are associated with syndromes like hereditary multiple exostosis.(2)

The lesion is composed of cortical and medullary bone with an overlying cartilage cap. Continuity of the osteochondroma with underlying bone cortex and medullary canal is a typical feature of osteochondroma. ${ }^{(3)}$

Osteochondroma is the tumor of developing skeleton. So, It often presents in young adults and its development usually stops with skeletal maturity. Most of the patients are asymptomatic and are diagnosed incidentally. The most common symptom of osteochondroma is cosmetic deformity. Complications associated with osteochondroma are bone deformity, fracture, adjacent vascular or neural injury, bursa formation, development of secondary osteoarthritis of the affected joints and malignant transformation.(1,4) There is increased risk of malignancy if the thickness of cartilage cap is 
more than $1 \mathrm{~cm}$.(5) Osteochondromas usually arise from metaphysic of long bones. The femur is the most commonly affected bone with distal involvement is more common than proximal involvement.(6) When flat bones are involved, the lesion will have cauliflower or expansile appearance. Depending upon the areas of osseous continuity between parent bone and osteochondroma, the lesions are classified into sessile and pedunculated types. If the dimension of base of the lesion is more than its length it is sessile type, If the dimension of base is less than its length than it is pedunculated type.

Plain radiograph is the modality of choice of diagnosis of osteochondroma. CT or MRI are needed in when the lesions are in unusual locations and to detect complications.

Differential diagnosis for epiphyseal osteochondroma is trevor's disease. Trevor's disease is also called dysplasia epiphysealis hemimelica. It is a type of dysplasia characterised by the occurrence of osteochondromas arising from epiphysis and asymmetric enlargement of multiple epiphysis.

Symtomatic osteochondroma can be treated with simple resection of the base of the tumor and cartilaginous tissue including the perichondrium surrounding the cap.

\section{REFERENCES:}

1. Murphey MD, Choi JJ, Kransdorf MJ, Flemming DJ, Gannon FH. Imaging of osteochondroma: variants and complications with radiologic-pathologic correlation. Radiographics. 2000; 20 (5): 1407-34.

2. Edelman RR, Hesselink JR, Zlatkin MB. Vol. 3. Philadelphia: Saunders Elsevier; 2006. Clinical magnetic resonance imaging. pp. 2320-27.

3. Resnick D, Kyriakos M, Greenway GD. Osteochondroma. In: Resnick D, eds. Diagnosis of bone and joint disorders. 3rd ed. Vol 5. Philadelphia, Pa: Saunders, 1995; 3725-3746.

4. D Van Linthoudt, L Malterre, A Pazera "[Bilateral knee osteoarthritis associated with supracondylar chondromas and popliteal osteochondromas].” Praxis (Bern 1994), 2003 Mar 19;92(12):541-6.

5. Ahmed AR, Tan TS, Unni KK, Collins MS, Wenger DE, Sim FH. Secondary chondrosarcoma in osteochondroma: report of 107 patients. Clin Orthop Relat Res 2003; 411 (411): 193-206.

6. Giudici MA, Moser RP, Jr, Kransdorf MJ. Cartilaginous bone tumors. Radiol Clin North Am 1993; 31: 237-259.

Figure 1: Plain radiograph shoulder AP view shows subtle bony outgrowth from ephiphysis of humerus (Arrow).

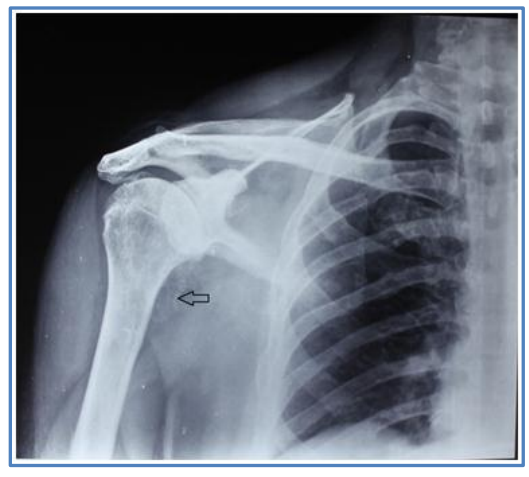

Fig. 1 


\section{CASE REPORT}

Figure 2: MRI T1 coronal image shows epiphyseal osteochondroma (Arrow).

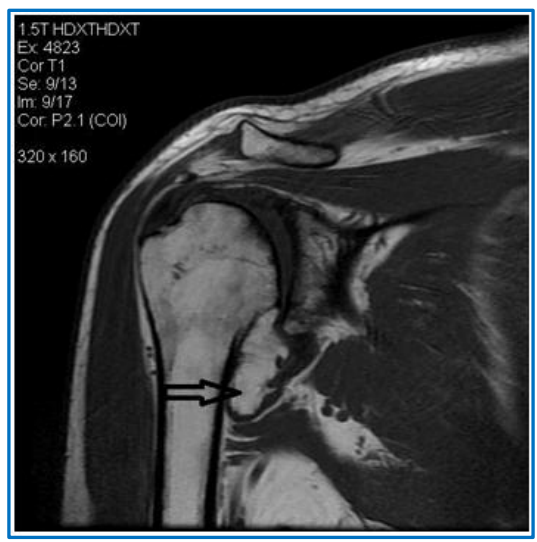

\section{Fig. 2}

Figure 3: MRI T1 coronal image shows communication of lesion with medullary cavity of bone (arrow).

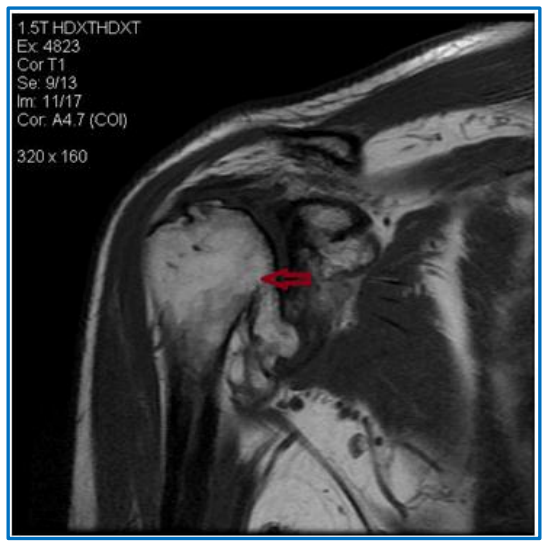

Fig. 3

Figure 4: MRI T2 coronal image shows epiphyseal osteochondroma.

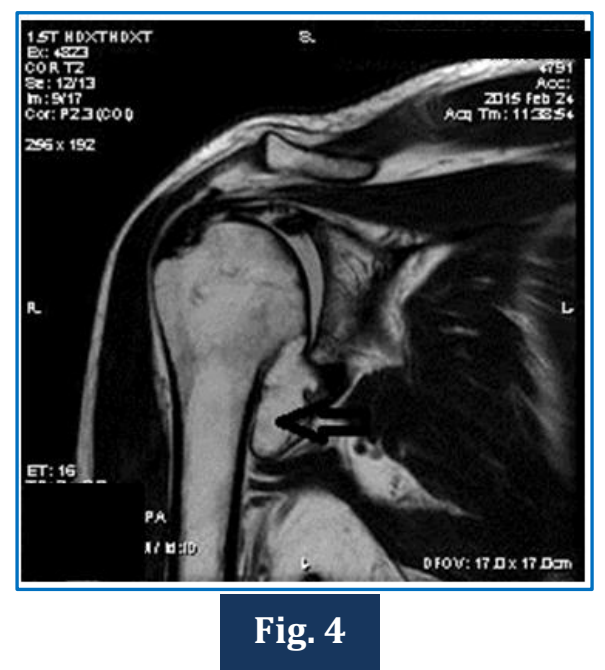




\section{CASE REPORT}

Figure 5: MRI STIR coronal image shows cartilage cap.

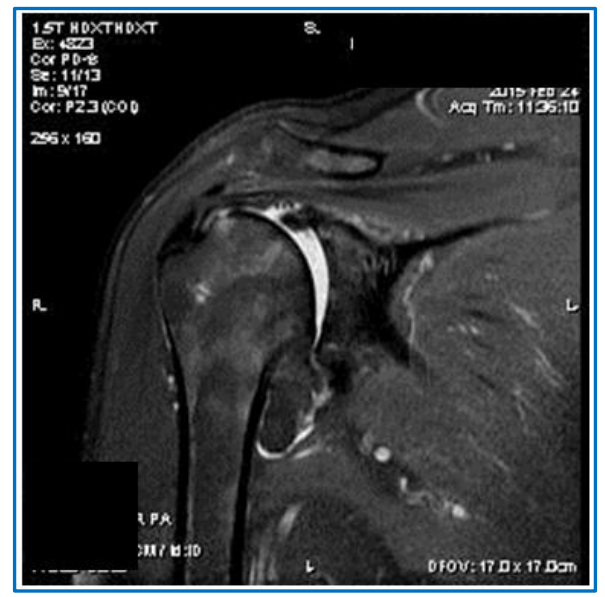

Fig. 5

\section{AUTHORS: \\ 1. Rajesh Kumar V. \\ 2. Vasu C. K. \\ 3. Pavithran V. K. \\ 4. Navas K. M. \\ 5. Fathima J.}

\section{PARTICULARS OF CONTRIBUTORS:}

1. Assistant Professor, Department of Radiology, KMCT Medical College.

2. Professor, Department of Radiology, KMCT Medical College.

3. Professor, Department of Radiology, KMCT Medical College.

\section{FINANCIAL OR OTHER} COMPETING INTERESTS: None
4. Associate Professor, Department of Radiology, KMCT Medical College.

5. Senior Resident, Department of Radiology, KMCT Medical College.

\section{NAME ADDRESS EMAIL ID OF THE CORRESPONDING AUTHOR:}

Dr. Rajesh Kumar V,

Department of Radiology, KMCT Medical College,

Manasaery, Mukkom,

Calicut, Kerala.

E-mail: kumar2476rd@gmail.com

Date of Submission: 25/03/2015.

Date of Peer Review: 26/03/2015.

Date of Acceptance: 11/04/2015.

Date of Publishing: 23/04/2015. 